\title{
Authoritative Questioning and Science Teaching in Saudi Arabian Context
}

\author{
Saeed Almuntasheri \\ School of Education, University of Queensland, Brisbane, Australia
}

Email address:

sas-1396@hotmail.com

\section{To cite this article:}

Saeed Almuntasheri. Authoritative Questioning and Science Teaching in Saudi Arabian Context. Science Journal of Education. Vol. 3, No. 3, 2015, pp. 43-49. doi: 10.11648/j.sjedu.20150303.11

\begin{abstract}
This qualitative study reports on the features of two teachers' questioning practices when teaching density for grade-six science elementary students. By adapting IRE questioning framework, this paper investigated issues in relation to the use of questioning as formative assessment strategy. The data revealed that teachers used authoritative questions to keep classroom interactions focused on what they expected to hear. The questioning implementations showed that teachers were unaware of students' conceptual change. It also revealed that teachers employed scaffolding strategies that support their authority. Implications for science educators include the need to develop appropriate models for teacher-student interactions that consider student contributions and encourage more dialogic teaching.
\end{abstract}

Keywords: Authority, Questioning, Scaffolding, Science Conceptions

\section{Introduction}

Science education literature emphasised that teachers commonly need more support to overcome their difficulties interacting with students in inquiry-based instructional settings (Alexander, 2005; Carlsen, 1991; Furtak, 2006). Despite the key role of the teachers' questions to coordinate classroom discourses, the traditional teacher's practice of authority lead to control the discourse moving through serious of questions that are consistent with teacher's planed agenda (Chin,2007). This can be via a constant low-level of questioning discouraging student engagement and conceptions. This strict control when teachers practice authoritative questions can potentially impact students' inquiry and knowledge-building experiences in science classrooms.

Many teachers tend to present science-teaching as a process of transmission of facts; these have to be memorized by the students, and the teachers ask the types of questions that support pre-determined plan (Chin, 2007). This is due, in part, to their concern for covering the content within the allotted time-period but it is also due to their lack of questioning skills, which could support their utilizing of the questioning process in inquiry-learning classes. Engaging teachers to learn about and reflect upon their questioning practice can support their questioning skills to position themselves less authoritatively in relation to students (Oliveira, 2010).

Students also require guidance in their thinking processes that involve their undertaking of various, science inquiry activities through encouraging more dialogic talk. One approach to promoting the dialogic process after eliciting the students' initial responses is to encourage them to discuss, to share responses with the teacher or peers and to engage them in more dialogic teaching(Alexander, 2005). The dialogic talk involves extended changes between teacher-and-students and students themselves, with further engaging in a number of “talk moves”'(Resnick, Michaels, \& O'Connor, 2010).This can be achieved by supporting teachers learning and designing specific strategies and types of questioning, which will act as the stimuli for discussion and which will provide opportunities for the students to create new ideas and to reconsider their existing knowledge in the social environment (Oliveira, 2010; Ruiz-Primo \& Furtak, 2006). The questions and prompts that the teachers use to structure their classroom interactions are significant forms of scaffolding (Christine Chin, 2007) .

The students' participation in classroom dialogue can be encouraged when the teacher takes actions that will elicit the students' ideas, and then act upon the initial response by 
validating it, and absorbing it into the ongoing classroom conversation without making an evaluative judgement about its correctness (Ruiz-Primo \& Furtak, 2006). This requires effective questioning-techniques and skills to respond to and to encourage thoughtful answers (Elliot, 1994). The questions posed and the following actions for dealing with the students' responses can strongly influence the students' engagement that is involved in solving shared-tasks during the inquiry-learning process. Coherent explanations of the phenomena in context are the goal of asking questions in inquiry-science rather than the process of collecting simple factual answers as still frequently occurs in the moretraditional classrooms (Chin, 2007\&Osborn, 2010).

In the primary school, it is important to encourage the students' discourses to present their own understandings. Buty and Mortimer (2008) distinguished between dialogic and authoritative talk based on the fact that in the dialogic talk "different ideas are acknowledged whether it is produced by a group of people or by a single individual" (p.1639). Unfortunately, teachers often neglect the students' efforts to form their own explanations or to express their own views (Hyman, 1980).

This is an exploratory study of Saudi teachers' current practices of questioning prior to their involvement in a professional learning course introducing them to teaching science based inquiry. It aims to understand the features of the participating teachers questioning when trying to grasp the form of authority to teaching science inquiry. This may help to investigate factors that can be addressed in the professional learning content. This study is built on previous work on questioning and classroom discourse (Alexander, 2005; Christine Chin, 2007; Ruiz-Primo \& Furtak, 2006). The findings of these studies showed the significance role of questioning in managing classroom discourse when teaching science as inquiry. Thus, this preliminary study was conducted to explore Saudi teachers questioning practices and to prepare them for enacting inquiry based learning reforms.

\section{Research Questions}

1) How did Saudi teachers enact authority when asking questions in science classes?

2) How did they use questioning as a scaffolding tool and how did their scaffolding strategies impact student conceptions?

\section{Methods}

\subsection{Participants}

This is a qualitative study of two primary teachers from two different schools who randomly selected in this pilot study prior to taking place in a professional learning course. This course aims to support Saudi teachers teaching science using the guided inquiry approach (Bybee, 2009). The two participant teachers were both primary-school science teachers who had taught for more than ten years. They were observed when teaching the density unit for grade six students. They taught science-classes; these had a teacherstudent ratio of approximately 1:15.

The two teachers are recently introduced to new Saudi National curriculum requesting them to teach the 5Es guided model. Before their involvement in the professional learning course, they were voluntarily agreed to observe their science classes. The parents of the students drawn from the two teacher classes were contacted and consent forms were also obtained prior to their participations.

\subsection{Classroom Observation}

One of the main objectives in using classroom observations in this study was to investigate how Saudi teachers employed the strategy of asking questions, how they allowed for the students' participation and, how they react after receiving the initial responses to allow for further learning. Both an audio-recorder and field notes were used to capture the teacher-student interactions and the teachers' use of questioning strategies to build the meaning of different, scientific concepts about density. Because the allocated time for teaching a specific unit in the Saudi curriculum must be the same, the researcher was only able to observe the teachers when teaching the density unit. The allocated time for teaching density in Saudi Arabia was four weeks so this researcher observed each teacher on four occasions. Different observation schedules were developed after timetables had been arranged with the two principals of the selected schools, which allowed this researcher to observe each teacher once a week.

\subsection{Data Analysis}

Observational data were analysed by going through the recordings, sorting out episodes involving question-answer interaction, and transcribing the interactions. The IRE was adapted to describe the questioning practices of the two teachers. The teacher initiation questions, student response, and the following form of evaluation were each coded before developing the findings. Each questioning conversation that included a particular subject-matter concept was evaluated via the resultant description. The conversation was ended when there was a transition to a new application of content such as; ask another student, and when there was a shift to a new subject-matter concept. The findings were developed by analysing teacher initiation questions and their following actions dealing with the received student responses. This helped to develop an understanding to define the functions of the questioning that was implemented by the two teachers.

\section{Results and Discussion}

\subsection{RQ1: Images of Teachers' Authority}

Classroom observations of the two teachers indicated that the purpose of questioning tended to elicit information and evaluate answers rather than at attempting to understand the 
students' own ideas and interpretations (Lemke, 1990; Mehan, 1979). This purpose was supported by the authority of the teachers, who claimed and stated knowledge that they anticipated that the students would accept without further debate (Van Zee \& Minstrell, 1997). Although the teachers might invite responses from the students, they generally discounted their responses as they focused solely on the scientific concept (Chin, 2007).

The following discussion provides an example of how teacher (A) implemented teacher-centered questioning. It begins by providing a completed transcript to understand the context of teacher-student interaction. This then followed by exploring the ways in which teacher used questions to elicit and direct student thinking to the expected right answers.

The episode below demonstrates how teacher (A) implemented his questioning whilst teaching the popcorn density investigation. The interaction with students showed how he controls the direction of the discussion until it was fully developed. This can thus be identified as a typical teacher-student interaction. Evidence for this type of interaction can be seen from the first turn from an I-R-E (initiation-response-evaluation) sequence at lines 1 to 3 and from the second turn at lines 3 to 5 .

1. T: Density is an important concept that depends upon both the volume and the mass of an object. Differences between these materials' densities will help to explain why some objects float and others sink in the water. But what do we mean by floating? I

2. $\mathrm{S}_{1}$ : When an object stays above the water's surface. $\mathrm{R}$

3. T: Correct. The water has a density of $1 \mathrm{~g} / \mathrm{cm}^{3}$. The substance floats when its density is less than $1 \mathrm{~g} / \mathrm{cm}^{3}$, but what will happen if objects weigh more than $1 \mathrm{~g} / \mathrm{cm}^{3}$ ? (E, answer his own question)/ I

4. $\mathrm{S}_{2}$ : These objects must have more density than the water. R

5. T: Yes. This is true $\mathrm{E}$

6. T: do they sink or float? (I/ moves to another student)

7. S: They sink. R

8. T: Now as you see, we have both popped and unpopped popcorn. What do you observe? (I/ The teacher places both corn in the water)

9. $\mathrm{S}_{3}$ : The unpopped corn floated. $\mathrm{R}$

10. T: How? Which one is the unpopped corn? I

11. $\mathrm{S}_{3}$ : The bigger corn. $\mathrm{R}$

12. T: Do you agree? (I/ the teacher moves to another student)

13. $\mathrm{S}_{4}$ : No. The bigger one is the popped corn. $\mathrm{R}$

14. T: True. So which of them has less density? E/ I

15. $\mathrm{S}_{4}$ : The popped corn. $\mathrm{R}$

16. $\mathrm{T}$ : In this activity, the popped popcorn floats because it is less dense than water. This density change was due to the volume change after popping the corn. When the volume increased, the density decreased and so became less than $1 \mathrm{~g} / \mathrm{cm}^{3}$ and this caused the popped popcorn's floatation. (E/ the teacher answers his own question)

17. T: So, how does the density change when the volume of the popped popcorn is increased? I

18. $\mathrm{S}_{5}$ : Decreased. $\mathrm{R}$

19. T: Which one has more volume? (Teacher points to both corns) I

20. $\mathrm{S}_{1}$ : The popped popcorn. $\mathrm{R}$

21. T: The volume of the corn increased dramatically after popping but, in the case of mass, there was no change. For example, when you pop $1 \mathrm{gm}$ of corn, its weight after popping will remain the same $(1 \mathrm{gm}) .(\mathrm{E} /$ the teacher answers his own question)

22. T: For the unpopped popcorn, there was no change in its original density, which was more than water, and so it sank.

\subsubsection{Elicitation with Evaluative Function}

Observation of the two teachers' classes revealed that they asked initiation questions to seek the right answers. In the previous teacher-students interaction, teacher (A) did not appear to use questions that search for students' prior knowledge or truly seek information about the student conceptions. The use of the IRE (initiation-responseevaluation) pattern of discourse did not appear to support the teacher's investigation of these prior conceptions but, rather, guided the discussion towards predetermined right answers or ask questions to recall what have been discussed.

The questions being asked to elicit responses were used to promote direct recalling or indirect, offered explanations. For example, teacher A asked for a response, which could have been anticipated from the explanation that was previously offered to the students. In the previous transcript (line 3), as he had already explained that a substance floats when its density is less than $1 \mathrm{~g} / \mathrm{cm} 3$ and he then asked about the objects that had greater density than $1 \mathrm{~g} / \mathrm{cm} 3$. This strategy did not appear to reveal any of the students' prior knowledge in regards to the floating or to the sinking concepts.

Asking the students questions to get them to make a prediction and then using follow-up questions that examined their predictions seemed to be an effective strategy for eliciting student misconceptions (Yin, Tomita, \& Shavelson, 2013). A demonstration of this activity by directly placing both popped and unpopped corn in the water may not provide sufficient opportunities for revealing the students' prior knowledge about the likelihood of the corn's floating or sinking (line 8). A student misconception only appeared after the teacher asked the question "What do you observe?" yet the teacher couldn't employ predictive questions to ascertain the rest of the students' pre-conceptions.

\subsubsection{Glossing over Student Responses with Rare Consideration of Student Contributions}

Rather than asking following questions to interpret the initial response provided by a student, the two teachers used different strategies to quickly direct the student thinking to the correct answer. One of these strategies was to check on a response and then move on to find the correct answer (see the following part of interaction)

1. T: Now as you see, we have both popped and unpopped popcorn. What do you observe? (I/ The teacher places 
both corn in the water)

2. $\mathrm{S}_{3}$ : The unpopped corn floated. $\mathrm{R}$

3. T: How? Which one is the unpopped corn? I

4. $\mathrm{S}_{3}$ : The bigger corn. $\mathrm{R}$

5. T: Do you agree? (I/ the teacher moves to another student)

6. $\mathrm{S}_{4}$ : No. The bigger one is the popped corn. $\mathrm{R}$

7. T: True. So which of them has less density? E/ I

8. $\mathrm{S}_{4}$ : The popped corn. $\mathrm{R}$

9. T: In this activity, the popped popcorn floats because it is less dense than water. This density change was due to the volume change after popping the corn. When the volume increased, the density decreased and so became less than $1 \mathrm{~g} / \mathrm{cm}^{3}$ and this caused the popped popcorn's floatation. (E/ the teacher answers his own question)

In the above example, teacher A did not seem to value or clarify meaning of what students have said. At line 2 the first student did not distinguish between the two types of corns (popped and unpopped). He did not attempt to understand or to ask the student for further interpretation when he, for example, had confused the volume of the two corns at line 4 . He checked on his answer and then asked another student who was able to provide the correct answer at line 6 . He then followed by asking question that supported a pre-determined plan on the basis of his authority "So which of them has less density?" This was followed by the teacher answering his own question before providing a final statement to close this particular assessment conversation.

Another strategy to direct the student to the right answer was to ask questions that were based on the information, which had been presented in the previous statement. The students were then able to answer these questions, which mainly required short or 'fill in the blanks' answers.

These questioning practices tended to support the direct presentation of scientific concepts and rarely elicited the students' conceptions. This did not seem to support teachers to value their student contributions to make what Sadler (1989) described as "qualitative judgments" about their student ideas. In the following text, for example, teacher (A) introduced the term "mass" when he stated, "in the case of mass, there was no change" and also explained the density change of the corn during the process of popping. He did not involve students to interact with the meaning of "weight" for he provided an example that helped the students to think about the mass as a quantity only. Hence, teacher (A) also did not consider the students' differentiation of weight and density (Smith, Maclin, Grosslight, \& Davis, 1997).

1. T: The volume of the corn increased dramatically after popping but, in the case of mass, there was no change. For example, when you pop $1 \mathrm{gm}$ of corn, its weight after popping will remain the same $(1 \mathrm{gm})$. (E/ the teacher answers his own question)

2. T: For the unpopped popcorn, there was no change in its original density, which was more than water, and so it sank.

This approach did not support the students' conceptual thinking about the underlying variable that had caused the density changes after popping the corn. Teacher (A) only related the reason for the unpopped popcorn's sinking to the overall density without emphasising the importance of volume, which was the main goal of the popcorn's investigation.

Conceptual change is most likely to take place when students are engaged in a gradual transformation of their mental representations (Alonso-Tapia, 2002). Teachers can embed their questioning through a process of formative assessment and can follow gradual steps that will elicit their students' thinking, make inferences about what that evidence indicates, before responding to the students' ideas (Furtak, 2012). Such processes require teachers to have the ability to identify and be able to deal with the wide range of the students' ideas that underlie their correct and incorrect responses.

\subsection{RQ2: Scaffolding learning Via Questioning}

Scaffolding necessitates an active involvement by the teacher, which has to be carefully adjusted to the learner's continuing development (Vygotsky, 1978). Such scaffolding needs to be situated around a student's existing zone of proximal development (ZPD). Sufficient scaffolding to keep the students' challenged will also offer them a myriad of opportunities to determine their own progress (Hogan, 1997). This means that teacher should not provide too much information but, rather, that offered information, which is appropriate for a specific point of interaction.

In the following discussion, teacher $\mathrm{B}$ introduced the students to an investigation into the density of blocks of different materials with constant volumes. The goal of this activity was to scaffold the students as they investigated how changing the masses of the same-sized blocks affected their densities.

Although the significant role of teacher questioning strategies in supporting students' learning, excessive instructional support has also been reported to have had a negative impact on learning (Papadopoulos, Demetriadis, Stamelos, \& Tsoukalas, 2011). This proved to be the case in this instance when teacher B tended to provide excessive information or asked too many lower-level questions in an effort to facilitate his students' learning. For example, he supplied his students with explanations regarding the similarities between the cubes' volumes and their different masses in line 1 of the following transcript. The students were also told how to use the mass and volume measurements to calculate density and then were asked specific questions to confirm the correctness of their calculations.

1. T: Today we will be calculating the densities of four different cubes. These cubes have the same volumes but they have different mass ( $\mathrm{T}$ drew a cube shape and identified the length, width and height).

2. T: We need to find the volume and the mass for each cube and then to find the density to understand why some sink or float in water.

3. T: How can you find the volume of a three-dimensional 
shape? (T distributed cubes to different groups)

4. $\mathrm{S}_{1}$ : We will measure all of the sides and add up their lengths.

5. $\mathrm{S}_{2}$ : We will multiply the length by the width.

6. T: For all cubes, you need to multiply its length by width by height.

7. $S_{2}$ : We will find the volume of one cube only because the other cubes will be the same

8. T: Yes. Excellent!

This part of the classroom talk appeared to influence the cognitive level of the following questions and thus restricted the students' thinking to the provided instructions. At line 1, teacher B told the students that all cubes have the same volume and this appeared to influence the student's response at line 7 in which he thought that finding the volume of one cube would be enough and, therefore, that there would be no need to calculate the volumes of the other cubes. In this example, the students were not challenged to explore the similarities between the volumes of these cubes but, rather, were simply provided with the required information for predicting this fact.

Teacher B then asked questions that directed the students' calculation process for finding the volume and mass and he also provided them with the density formula to find the density of each cube as can be seen in the following teacherstudent interaction,

9. What was length of each side?

10. $\mathrm{S}_{3}$ : The length is 3 .

11. T: What about the volume? Did you multiply width by length by height?

12. $\mathrm{S}_{3}$ : Yes. It was 27.

13. T: What is the unit of the volume?

14. $\mathrm{S}_{3}$ : liter

15. T: Why? Is it a liquid? (Pointing to another student).

16. $\mathrm{S}_{4}$ : No. It is $\mathrm{cm}$.

17. T: Solid volume is measured using cubic centimeters $\left(\mathrm{cm}^{3}\right)$ or cubic meters $\left(\mathrm{m}^{3}\right)$.

18. T: As you know the formula of density is $d=\frac{m}{v}$ (Teacher wrote the formula on the board).

19. T: We have already calculated the volume, so what thing do we need now to find the density?

20. $\mathrm{S}_{\mathrm{s}}$ : The mass.

In the above transcript, the questions that were used tended to direct students toward the expected answers. Teacher B seemed to ask for the length of the cube to support the student's calculation of the total volume (lines 9 to 12), and then asked a question that helped the student to anticipate the answer (line 15, is it a liquid?). He also answered his own question regarding the unit of volume when he encountered an incomplete student's response (line 17). He then provided the density formula and asked a leading question "What thing do we need to find the density?" to help a student to identify the missing variable in the calculation process, which was the mass (lines 18 to 20). The students were then provided with a data table for recording the mass and volume of each cube and they then used the density formula to find their densities. Teacher B directed his students to compare each cube's density with the density of water $(1 \mathrm{gm} / \mathrm{cm} 3)$ to justify its floating or sinking.

21. $\mathrm{T}$ : What was the density of wood?

22. $\mathrm{S}_{5}: 0.63 \mathrm{~g} / \mathrm{cm}^{3}$.

23. T: The density of water is $1 \mathrm{~g} / \mathrm{cm}^{3}$. If the density of an object is less than density of water then this object will float.

24. Now we will see what will happen to the cube of wood. (T placed the cubes in the water).

25. T: Why does the wood float?

26. $\mathrm{S}_{6}$ : Wood is lighter than water.

27. T: True. But what happens to its density?

28. T: Which one has the higher density - the wood or the water?

29. $\mathrm{S}_{7}$ : The water.

30. T: That is why. The wood has a lower density of only $0.63 \mathrm{~g} / \mathrm{cm}^{3}$ when compared with $1 \mathrm{~g} / \mathrm{cm}^{3}$ for the water and thus it floated.

As can be shown from the previous transcript, teacher B used questions and instructions that provided a high level of support to the students and directed their responses. He followed a step-by-step approach in reaching his planned goal, and emphasised the traditional calculation of density. His questions asked the students to either provide short answers that were based on the students' recorded data (lines 10 and 11 and lines 20 and 21) or simply asked them to recall information that had been previously provided to them as in lines 14 and in 17 to 18 .

For appropriate scaffolding to occur, the teacher must utilise three, key characteristics of scaffolding, namely: contingency, fading, and transfer of responsibility (Pol, Volman, \& Beishuizen, 2010). Diagnosing the students' levels of understanding is an important tool of contingency. The fading process is characterised by the teacher's decreasing of the level of support given to the students over time, which is based on the development of their performance of the task. The teacher's responsibility should be gradually transferred during the fading process with a commensurate increase in the students' control of their own learning by the end of the fading phase (Pol et al., 2010).

The classroom interaction that was directed by the two teachers did not appear to endeavour to transfer the responsibility of learning to their students. There was no clear diagnosing of or an attempt to understand the students' prior knowledge. Their pre-conceptions, when they appeared, were simply discouraged and/or accepted without change. The student responses were rarely used to develop student conceptions but in many cases teachers moved on to another student or changed the question. At line 25, for example, teacher B asked, "Why does wood float?", but the student's response did not differentiate between weight and density. He then asked a specific question about density "But what happened to its density?" and followed this with yes/no question, which offered additional help and thus made the answer accessible. The student's level of prior knowledge was not, however, diagnosed. 


\section{Conclusion}

The above findings showed that science instructors need to develop higher levels of awareness to enact authority in classroom encounters. Observing the two teacher classrooms indicated their dominance of the third move "Evaluation" in this IRE sequence. They mainly considered their students' responses by simple evaluation, or by directing these responses to the teacher's expected right answers. After receiving a response teachers appear to guide students to the correct answer rather than to inform their current conceptions and "in such cases the cognitive potential of exchanges was lost" (Alexander, 2005, p. 9).

With incorrect responses teachers glossed over the response but without paying attention to its meaning. This included the disregard of students' misconceptions and moving from one student to another or from one question to another to keep the discussion focused on what the teacher is expected to hear. As a result, students tended to be waiting for the teacher providing them with a final explanation and summary about the main lectured ideas.

Teachers' lack of scaffolding strategies were found to impact their questioning strategies used to respond to the students' thinking. Without appropriate initiation questions, students' existing knowledge and skills were rarely examined. Rather, asking questions with evaluative function appear to discourage students from sharing their genuine ideas related to the concept under investigation.

After receiving a response, teachers in this study utilised strategies that directed student responses to the teacher's lesson plan. These included responding with questions of 'yes/no, and fill in blank' types or to recall what have been conveyed to them. These strategies and types of questions did not seem to give space for interaction in the student zone of proximal development(Vygotsky, 1978). Rather, the students' responses were highly scaffolded by teachers leading to close the questioning conversations.

Oliveira (2010) argues that for teachers "to promote thoughtful and reflective learning, they need to establish a relationship with students not based on authority but on intellectual partnership "(Oliveira, 2010, p. 447). This awareness can enable science teachers to shift their practice of authority-based classroom relations to talking as inquirybased learning contexts demand.

Teachers' social understanding of questioning can be a good way to comprehend the relational or interactional nature of authority in educational contexts. It is the act of questioning that distinguishes conversation from dialogue and the critical issue is that questions that rise from the answer provided by students (Alexander, 2005). Teacherstudent dialogue requires logical progression in a way that both develop knowledge building on each other's contributions (Wolfe \& Alexander, 2008). This demands teachers to ensure guiding the pedagogical content while ensuring that students' contributions are "woven into the unfolding discourse" (Wolfe \& Alexander, 2008, p. 9).

\section{References}

[1] Alexander, R. (2005). Culture, dialogue and learning: Notes on an emerging pedagogy.Paper presented at the Conference of the International Association for Cognitive Education and Psychology. University of Durham, UK.

[2] Alonso-Tapia, J. (2002).Reconsidering conceptual change: Issues in theory and practice. In M. Limon, \& L. Mason (Eds.), Knowledge assessment and conceptual understanding (pp. 389-413). Madrid,Spain: Dordrecht: Kluwer.

[3] Burns, C., \& Myhill, D. (2004). Interactive or inactive? a consideration of the nature of interaction in whole class teaching. Cambridge Journal of Education, 34(1), 35-49. doi: 10.1080/0305764042000183115

[4] Buty, C., \& Mortimer, E. F. (2008). Dialogic/authoritative discourse and modelling in a high school teaching sequence on optics. International Journal of Science Education, 30(12), 1635-1660.

[5] Bybee, R. W. (2009,January). The BSCS 5E instructional model and 21st century skills. Paper prepared for the Workshop on Exploring the Intersection of Science Education and the Development of 21st Century Skills, National Research Council. Washington.

[6] Carlsen, W. S. (1991). Questioning in Classrooms: A Sociolinguistic Perspective. Review of Educational Research, 61(2), 157. doi: 10.2307/1170533

[7] Chin, C. (2007). Teacher questioning in science classrooms: Approaches that stimulate productive thinking. Journal of Research in Science Teaching, 44(6), 815-843. doi: 10.1002/tea.20171

[8] Chin, C., \& Osborne, J. (2010). Supporting Argumentation Through Students' Questions: Case Studies in Science Classrooms. Journal of the Learning Sciences, 19(2), 230-284. doi: $10.1080 / 10508400903530036$.

[9] Edwards, D., \& Mercer, N. (1987). Common knowledge. The development of understanding in the classroom. London: Methuen.

[10] Elliot, A. (1994). Teaching Questioning and Learning. Teaching Education, 6(1), 183-184. doi: 10.1080/1047621940060124

[11] Fulmer, G. W. (2013). Constraints on Conceptual Change: How Elementary Teachers' Attitudes and Understanding of Conceptual Change Relate to Changes in Students' Conceptions. Journal of Science Teacher Education, 24(7), 1219-1236. doi: 10.1007/s10972-013-9334-3.

[12] Furtak, E. M. (2006). The problem with answers: An exploration of guided scientific inquiry teaching. Science Education, 90(3), 453-467. doi: 10.1002/sce.20130.

[13] Furtak, E. M. (2012). Linking a learning progression for natural selection to teachers' enactment of formative assessment. Journal of Research in Science Teaching, 49(9), 1181-1210. doi: 10.1002/tea.21054.

[14] Grosslight, L., Maclin, D., \& Davis, H. (1997). Teaching for Understanding: A Study of Students' Preinstruction Theories of Matter and a Comparison of the Effectiveness of Two Approaches to Teaching About Matter and Density. Cognition and Instruction, 15(3), 317-393. doi: 10.1207/s1532690xci1503_2. 
[15] Hogan, K. E., \& Pressley, M. E. (1997). Scaffolding student learning: Instructional approaches and issues: Brookline Books.

[16] Hyman, R. T. (1980). Fielding Student Questions. Theory into Practice, 19(1), 38-44. doi: 10.1080/00405848009542870.

[17] Kearsley, G. P. (1976). Questions and question asking in verbal discourse: A cross-disciplinary review. Journal of Psycholinguistic Research, 5(4), 355-375.

[18] Keeley, P. (2013). Is it melting? Formative assessment for teacher learning. Science and Children, 51(3), 26.

[19] Lemke, J. L. (1990). Talking science: language, learning, and values. Norwood, N.J: Ablex.

[20] Long, M. H., \& Sato, C. J. (1983). Classroom foreigner talk discourse: Forms and functions of teachers' questions. In: H.W. Seliger \& M.H. Long (Eds.), Classroom oriented research in second language acquisition(pp.268-285). Rowley, MA: Newbury House.

[21] Mehan, H. (1979). Learning lessons: social organization in the classroom. Cambridge, Mass: Harvard University Press.

[22] Myhill, D., \& Dunkin, F. (2005). Questioning Learning. Language and Education, 19(5), 415-427. doi: $10.1080 / 09500780508668694$.

[23] O'Connor, M. C., \& Michaels, S. (1993). Aligning academic task and participation status through revoicing: Analysis of a classroom discourse strategy. Anthropology and Education Quarterly, 24, 318-318.

[24] Oliveira, A. W. (2010). Improving Teacher Questioning in Science Inquiry Discussions Through Professional Development. Journal of Research in Science Teaching, 47(4), 422-453. doi: 10.1002/tea.20345

[25] Papadopoulos, P. M., Demetriadis, S. N., Stamelos, I. G., \& Tsoukalas, I. A. (2011). The value of writing-to-learn when using question prompts to support web-based learning in illstructured domains. Educational Technology Research and Development, 59(1), 71-90. doi: 10.1007/s11423-010-9167-0.

[26] Pol, v. d. J., Volman, M., \& Beishuizen, J. (2010). Scaffolding in teacher-student interaction: a decade of research. Educational Psychology Review, 22(3), 271-296. doi: 10.1007/s10648-010-9127-6.

[27] Posner, G. J., Strike, K. A., Hewson, P. W., \& Gertzog, W. A. (1982). Accommodation of a scientific conception: Toward a theory of conceptual change. Science Education, 66(2), 211227. doi: $10.1002 /$ sce. 3730660207 .
[28] Resnick, L. B., Michaels, S., \& O’Connor, C. (2010). How (well-structured) talk builds the mind. In In D.Preiss \& R. Sternberg (Eds.), Innovations in educational psychology: Perspectives on learning, teaching and human development (pp. 163-194). New York, NY: Springer.

[29] Roehrig, G. H., \& Luft, J. A. (2004). RESEARCH REPORT: Constraints experienced by beginning secondary science teachers in implementing scientific inquiry lessons. International Journal of Science Education, 26(1), 3-24.

[30] Ruiz-Primo, \& Furtak. (2006). Informal formative Assessment and scientific Inquiry: Exploring teachers' practices and student learning. Educational Assessment, 11(3-4), 237-263.

[31] Sadler, D. R. (1989). Formative assessment and the design of instructional systems. Instructional Science, 18(2), 119-144. doi: 10.1007/BF00117714.

[32] Taber, K. S. (2011). Constructivism as educational theory: Contingency in learning, and optimally guided instruction. In Hassaskhah J. (ed.), Educational Theory (pp. 39-61). New York: Nova.

[33] Van Zee, \& Minstrell. (1997). Using questioning to guide student thinking. The Journal of the Learning Sciences, 6(2), 227-269.

[34] Vygotsky, L. S. (1978). Mind and society: The development of higher mental processes: Cambridge, MA: Harvard University Press.

[35] Wang, C. H. (2005). Questioning skills facilitate online synchronous discussions. Journal of Computer Assisted Learning, 21(4), 303-313.

[36] Wolfe, S., \& Alexander, R. J. (2008). Argumentation and dialogic teaching: alternative pedagogies for a changing world. London, UK: FutureLab (Beyond Current Horizons).

[37] Wu, K.-y. (1993). Classroom interaction and teacher questions revisited. RELC Journal, 24(2), 49-68.

[38] Yin, Y., Tomita, M. K., \& Shavelson, R. J. (2014). Using Formal Embedded Formative Assessments Aligned with a Short-Term Learning Progression to Promote Conceptual Change and Achievement in Science. International Journal of Science Education, 36(4), 531-552. doi: 10.1080/09500693.2013.787556.

[39] Yip, D. Y. (2004). Questioning skills for conceptual change in science instruction. Journal of Biological Education, 38(2), 76-83. 